\title{
Pediatric chronic fatigue syndrome: current perspectives
}

This article was published in the following Dove Press journal:

Pediatric Health, Medicine and Therapeutics

\author{
Esther Crawley \\ Centre for Child and Adolescent \\ Health, Bristol Medical School, \\ University of Bristol, Bristol, UK
}

Correspondence: Esther Crawley Centre for Child and Adolescent Health, University of Bristol, Oakfield House, Oakfield Grove, Bristol BS82BN, UK Tel +440 II7331 4099

Email esther.crawley@bristol.ac.uk

\begin{abstract}
Pediatric chronic fatigue syndrome is an important illness as it is relatively common and also very disabling with a wide range of impacts on the child, the family, and health care systems. It is a complicated illness but the majority of children get better with specialist treatment. This literature review provides an update on the epidemiology of chronic fatigue syndrome / myalgic encephalomyelitis, including factors associated with it, and discusses the current evidence for treatment.
\end{abstract}

Keywords: CFS, ME, myalgic encephalomyelitis, epidemiology, pediatric

\section{Introduction}

\section{What is chronic fatigue syndrome/myalgic encephalomyelitis (CFS/ME)?}

Children and adolescents with CFS have severe disabling fatigue that lasts for at least 3 months. They have additional symptoms, including headaches, sleep problems, cognitive problems, sore throat, muscle aches and pains, nausea, and dizziness. Post-exertional malaise is a core symptom and the most useful when making a diagnosis. Children experience an increase in fatigue, malaise and symptoms after an increase in exertion. For many, this means they attend 1 or 2 days of school, before becoming too unwell to attend school at all. Some children are severely affected and post-exertional malaise presents as an increase in symptoms after, for example, taking a shower or walking down the stairs. Other symptoms that are almost universal in children and adults are cognitive dysfunction and disturbed/ unrefreshing sleep. ${ }^{1,2}$ Table 1 lists the different clinical and research definitions used to define CFS/ME.

\section{Impact of CFS/ME}

$\mathrm{CFS} / \mathrm{ME}$ can have a devastating impact on children in terms of quality of life, ${ }^{5}$ school, social life, and family function ${ }^{6,7}$ at the crucial time of development. It also has an impact on health service provision. Children with CFS/ME have an increase in medical consultations, tests, and prescriptions, up to five years before receiving a diagnosis. ${ }^{8}$ Most children attending a specialist service attended $40 \%$ of school or less. ${ }^{9}$ About one-third of them suffer from comorbid anxiety and/or depression. ${ }^{10,11}$ Children suffer social isolation, give up hobbies, and experience significant pain in addition to their fatigue. $^{12}$ 
Table I Definitions used to define CFS/ME

\begin{tabular}{lll}
\hline Criteria & Duration & Required symptoms \\
\hline Oxford $(199 \mid)^{74}$ & $\geq 6$ mo & Cognitive dysfunction \\
CDC, Fukuda $(1994)^{75}$ & $\geq 6$ mo & 4 of 8 symptoms concurrently for $\geq 6 \mathrm{~m}$ \\
NICE $(2007)^{56}$ & $\geq 4$ mo & I of 10 symptoms listed \\
ME: ICC & Not defined & PENE plus I symptom from each of neurological, immune/gastrointestinal/genitourinary \\
& & impairment/energy metabolism categories \\
IOM $^{\mathrm{b}}(2015)^{4}$ & $\geq 6$ mo & Post-exertional malaise AND sleep disturbance AND cognitive dysfunction AND/OR \\
& & orthostatic intolerance \\
\hline
\end{tabular}

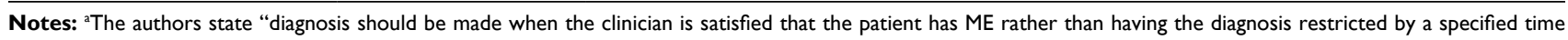
factor"; bsuggested a new name: Systemic Exercise Intolerance Disease (SEID).

Abbreviations: ICC, International Consensus Criteria; IOM, Institute of Medicine; ME, myalgic encephalomyelitis; PENE, post-exertional neuroimmune exhaustion; CDC, Centre for Disease Control and Prevention; mo, months; NICE, The National Institute for Health and Care Excellence.

\section{Epidemiology}

\section{Prevalence}

Many adolescents have severe fatigue but the prevalence of CFS is less common. Between $34 \%$ and $41 \%$ of adolescents report feeling "much more tired and worn out than usual" ${ }^{13,14}$ The prevalence of CFS in children and adolescents is between $0.11 \%$ and $4 \% .{ }^{14-19}$ There are two peaks for CFS, one in children and adolescents (10-19 year olds) and one in 30 -year olds. ${ }^{20}$ The different prevalence rates reflect different diagnostic criteria and the different research methodologies used to identify cases. Population surveys report higher prevalence rates than surveys relying on self-report, or studies that recruit participants from clinical settings requiring a clinical diagnosis. This may be because patients experience barriers in obtaining a diagnosis ${ }^{21}$ and treatment, which may partly be due to the fact that doctors find it difficult to make a diagnosis. ${ }^{22}$

\section{Incidence}

There is little known about the incidence of pediatric CFS/ME. The estimated incidence of pediatrician-diagnosed CFS/ME in the Netherlands is $0.01 \%{ }^{17}$ but this is likely to be lower than the true incidence as not all children with CFS get a diagnosis. ${ }^{19}$ In the UK, an incidence of $0.36 \%$ in a 4-6 month window has been reported but the number of cases was low $(4 / 1096)^{23}$ and therefore, the true incidence of CFS/ME remains uncertain.

\section{Factors associated with pediatric CFS/ME Gender}

CFS is equally common in boys and girls aged $\leq 13$ years. ${ }^{2,18,24}$ The prevalence then appears to increase in females but not males after puberty; so, based on gender, CFS is $2-3$ times more common in females in older teenagers and adults.

\section{Social adversity}

CFS was previously considered to be an illness that only affected those of upper socio-economic classes and in the
1980 s, it was nicknamed "yuppie flu". This may reflect successful health-seeking behavior. However, as with many chronic illnesses, social adversity is a risk factor for CFS. Adversity in pregnancy increases the risk of developing CFS in 13 and 16 olds with odds ratios (OR) between 1.10 and 1.20 per unit family adversity index. ${ }^{14,18}$

\section{Genetic factors}

Twin studies consistently show that genetic factors are an important risk factor for CFS. In adults, monozygotic (identical) twins have a higher concordance rate compared with dizygotic twins. For example, in a study of 146 femalefemale twin pairs, a monozygotic correlation of 0.55 was reported compared with a dizygotic correlation of $0.19 .{ }^{25} \mathrm{In}$ a larger study of 1004 adult twins, the equivalent correlations were 0.43 and 0.16 , respectively. A large component of the genetic variation for fatigue is not shared by other forms of distress. ${ }^{26}$ These correlations in twin studies are higher in children than in adults, suggesting that children may be more genetically "loaded", which may explain why they get CFS earlier in life.

\section{Maternal mood}

Mothers of children with CFS have high levels of comorbid mood disorder. ${ }^{7}$ This could be secondary to the impact this illness has on their child and family, which includes: social isolation, lack of understanding, marital tension, concern about their child's distress, and loss of earnings. ${ }^{7}$ However, maternal mood in early childhood (pregnancy to age 6) increases the risk of developing CFS in adolescence. ${ }^{27}$ There are several possible explanations for this, including: increased susceptibility to fatigue because of in utero or early-life epigenetic effects; change in activity because of maternal mood; and change in questionnaire response because of maternal mood and co-segregation of genetic risk factors for mood and fatigue. 


\section{Infection}

Infection is a known risk factor for developing CFS in adults and children. The association of CFS with Epstein-Barr virus is well described with rates of $13 \%, 7 \%$, and $4 \%$ at 6 , 12 , and 24 months, respectively, after infection. ${ }^{28}$ All types of gastrointestinal infections increase the risk of developing CFS in adults..$^{29}$ It seems likely that it is the severity of the infection rather than the type of infection that is important. ${ }^{30}$

\section{Comorbid mood disorders}

Up to one-third of children with CFS have significant problems with anxiety and/or depression. ${ }^{2,10,11}$ Anxiety is more common in children with CFS/ME compared with those with other long-term conditions such as juvenile idiopathic arthritis. ${ }^{31}$ Those with low mood are more disabled, have worse fatigue, and increased pain compared with those with only CFS. ${ }^{11}$ In many cases, depression appears to develop because of the impact CFS has on the young person's life in terms of schooling, friendship groups, hobbies, and sport. ${ }^{32-34}$ They describe a sense of loss, restriction in activities, and change in their social environments (e.g., negative experiences with their peers), which contribute to their low mood..$^{32}$ However, we do not know which comes first in all cases. ${ }^{35}$ The evidence is conflicting on whether depression worsens prognosis ${ }^{36-42}$ in adults, and no data have been found on whether depression changes outcome in children. ${ }^{43}$ But it is plausible that comorbid mood disorders may make recovery from CFS/ME less likely.

\section{Hypermobility}

The relationship between CFS and hypermobility is unclear, with two relatively small studies providing conflicting results. ${ }^{44,45}$

\section{Differences to adult CFS/ME}

Children under 12 years old are less likely to describe $\operatorname{cog}$ nitive problems or problems sleeping compared to adults. But they are more likely to complain of sore throats. ${ }^{2}$ The symptom of post-exertional malaise is less often reported in this younger age group, but this may be an issue in understanding what post-exertional malaise is in younger children. Adolescents are more likely to have headaches compared with adults and less likely to have pain, tender lymph nodes, palpitations, dizziness, and general malaise. ${ }^{2}$

The most interesting difference and the most important issue to highlight to parents (particularly those with CFS themselves) is that adolescents are more likely to improve and recover compared with adults. Most pediatric studies report significant improvement or recovery in between $54 \%$ and $94 \%$ of those treated. ${ }^{46}$ In the largest pediatric trial to date, $75 \%$ of children were attending full-time school at 6 months and $63 \%$ were considered recovered on both primary and secondary outcomes, which included answering "yes" on self-rated "I have completely recovered" or "I feel much better but still experience some symptoms". This compares with much lower recovery rates in adults. ${ }^{47}$ The reasons for this difference are unknown but likely to be multifactorial.

\section{The complexities of CFS/ME}

CFS is not one homogenous illness. In adults, 3-5 different phenotypes (clusters of symptoms) have been described. ${ }^{1,48-52}$ Phenotypes can include observational data (e.g., body mass index) as well as self-reported symptoms. ${ }^{53}$ In children, three phenotypes have been described ${ }^{54}$ that are associated with markers of severity, but it is not yet known if they predict outcome. Two studies ${ }^{1,55}$ have replicated findings and there is some consistency in that most studies describe a polysymptomatic phenotype, a sore throat and painful lymph node phenotype, and a musculoskeletal pain phenotype.

CFS is also complicated by the association with comorbid conditions. These include fibromyalgia, irritable bowel syndrome, migraine, and mood disorders. Some of these may be secondary to the illness (e.g., anxiety and depression), but some are commonly associated with CFS and may represent common causality, overlapping symptoms, and therefore difficulty with diagnosis or different care pathways.

Treatment and research are further complicated by the range of severity experienced by patients with CFS. While all patients must be significantly impaired before being diagnosed with CFS, some can attend school full time (but do nothing else outside school) while others are unable to get out of bed. Few research studies have been conducted in patients who are severely affected, and little is known about effective treatments in this patient group.

\section{Diagnosis and treatment}

The diagnosis of CFS relies on the typical clinical presentation and the exclusion of other causes of fatigue. A diagnosis can be made by taking a thorough history, examining the patient, and using blood tests to screen for other causes of fatigue. ${ }^{56,57}$ Assessment should include an assessment of mood disorders. These can be co-morbid (exist alongside a diagnosis of CFS) or be the primary cause of the fatigue which would exclude a diagnosis of CFS. Clinical assessment may also identify other areas that require further investigation (e.g., imaging if the child has persistent headaches). Treatment can start while investigations continue. ${ }^{56}$ 
Systematic reviews have consistently shown that the best evidence for treatment benefit in adults is Cognitive Behavioral Therapy (CBT) and Graded Exercise Therapy (GET) ${ }^{58-60}$ The situation is less clear in children. ${ }^{61,62}$ There are five randomized controlled trials that demonstrate benefit for children with CFS using CBT. One small pilot study ${ }^{63}$ $(n=22)$ investigated the effectiveness of Graded Aerobic Exercise therapy compared with progressive resistance training. While this trial reported benefits in quality of life and physical capacity in both arms, it was not powered to test differential effectiveness between treatments. While Activity Management is a recommended treatment approach in the $\mathrm{UK},{ }^{56}$ there are no trials for testing its efficacy in children.

CBT, GET, and Activity Management all include behavioral approaches to help children and adolescents improve their sleep and regulate their activity. Activity Management aims to help children and adolescents manage all activities and GET focusses on physical activity. CBT uses both a behavioral approach for activity and sleep, and a cognitive approach to challenge unhelpful thoughts, assumptions, and beliefs about, for example, the meaning of symptoms. ${ }^{64}$ Advice on sleep includes setting consistent wake-up times, reducing excessive sleep to improve sleep quality, and limiting daytime sleep to improve nighttime sleep. This should improve sleep and return the disordered diurnal variation in cortisol seen in adolescents with $\mathrm{CFS}^{65}$ back to normal. ${ }^{66}$ Strategies to improve exercise and activity are based on changing a boom-bust pattern of exercise, to a stable baseline of activity and exercise. This usually means that children and adolescents reduce exercise on good days in the short term. This reduces post-exertional malaise (or payback). Once activity/exercise is stable, they can steadily increase activity or exercise over time. ${ }^{56}$

\section{Pain}

Significant chronic pain is common in pediatric CFS, with $9 \%-20 \%$ of patients experiencing pain ratings of $75 / 100$ or $4 / 4$ on Likert scales. ${ }^{2}$ Most trials in adults with CFS suggest that pain is a poor prognostic factor but there is currently no evidence on the best method for treating pain in patients with CFS. The pain experienced in CFS is very similar to, and can be treated as, chronic pain. Clinicians can consider referral to a specialist pain management clinic and can consider medical treatment used for chronic pain. Some children seem to find amitriptyline helpful, although no trials have tested this in children. Amitriptyline should be started at a low dose and increased slowly. Some of the side effects of amitriptyline such as drowsiness can be helpful for those with pain and sleep problems; however, other children find that amitriptyline increases their fatigue. Opiates should not be prescribed to children with $\mathrm{CFS} / \mathrm{ME}$ and chronic pain because of side effects.

\section{Nausea and eating disorders}

Approximately $40 \%$ of children with CFS experience significant nausea ${ }^{2}$ and many develop subsequent problems with eating. CFS and eating difficulties can develop into a vicious cycle where not eating makes the fatigue worse and the fatigue and nausea make eating difficult. ${ }^{67}$ Adolescents say that their eating difficulties are caused by abdominal pain, being tired, and changes in their sense of taste and smell. ${ }^{67}$ There are no trials for investigating what treatments are effective, but current guidance ${ }^{56}$ suggests that eating little and often can be helpful.

While some children struggle to eat because of nausea, in others, increasing weight (presumably due to decreased activity) is a problem. Children with CFS assessed in a specialist clinic were found to be at a greater risk of developing obesity compared with healthy children (OR 2.31 at 13 years and 4.07 at 16 years).$^{68}$ No increased risk was found in those identified as having chronic disabling fatigue in a birth cohort, suggesting the risk of developing obesity is only present for children and adolescents with CFS that require specialist care.

\section{Cognitive problems}

The majority of children $(86.7 \%$ of adolescents and $76.5 \%$ of primary school children) complain of cognitive (memory and concentration) problems that are frequently described as brain fog. ${ }^{2}$ Two relatively small studies have shown different problems with attention, which may be due to the different methods of assessment as well as the small sample size. ${ }^{69,70}$ One demonstrated problems with sustained attention, switching attention, divided attention, auditory learning, and immediate recall compared with healthy children, and the other described problems with alternative attention and not divided or sustained attention. Children often report being fatigued by school work and this is consistent with one imaging study in children with CFS, which described increased frontal activation in Japanese children with CFS while performing a dual verbal task to assess divided attention. This suggests that the brain may require increased recruitment (cognitive compensation) to compensate for poorer task performance. ${ }^{71}$ Some of the abnormalities improved as children's fatigue improved after CBT; however, this is only one small study and the results need to be replicated. ${ }^{71}$ General strategies to help children with attention difficulties may be helpful and 
include attention process training, working on the school environment to help children maintain attention, as well as strategies to improve memory, including overviews, slowing the pace of new information, and providing verbal information with visual prompts. ${ }^{57,72}$

\section{Dizziness and orthostatic symptoms}

Forty-three percent of primary school children and 30\% of adolescents experience dizziness as a significant symptom and may faint when standing or have an increase in symptoms after hot baths. Treatment should start with behavioral methods, including increasing activity and movement, increasing fluid intake to 2-3 L a day, and increasing salt intake. ${ }^{57}$ Occasionally, medication can be used depending on the response to behavioral approaches and the symptoms described. ${ }^{57}$

\section{Comorbid mood disorders}

There is no evidence for the best methods to treat comorbid mood disorders in pediatric CFS. While current guidance suggests that they should be treated following normal clinical practice for low mood and anxiety, this may be in conflict with the approach for CFS. CBT for depression and CBT for CFS have similarities but also differences. ${ }^{64}$ The differences include the formulation of the problem, the therapeutic goals and the impact, and the use of activity and the cognitive focus. ${ }^{64}$ It is the differences in the impact and use of activity that may determine different treatment approaches. For example, patients with CFS are usually advised to do the same activities every day and then to gradually increase them. At the start, this will mean that they decrease activities and exercise on good days to avoid post-exertional malaise (or payback). This may conflict with treatment for depression where doing an enjoyable activity may be more important than limiting exercise.

\section{Conclusion}

Pediatricians need to remember that pediatric CFS is common but treatable. The diagnosis may be harder in primary school children as it may present differently from CFS in adolescents. Response to treatment is better than in adults, and children and adolescents deserve to be offered the range of treatment currently available.

\section{Problems with current research}

Research into this important illness is hampered by small sample sizes, different definitions, and the lack of a coordinated approach. CFS is probably not one illness, and it is likely that the different phenotypes are due to different underlying biological pathways requiring different treatment approaches. This may explain the relatively low response rate to current treatments. To develop better treatments, we need larger trials with carefully characterized participants to understand more about treatment response. We need to develop treatments in the areas identified previously where there is no evidence for effective treatment. This includes the treatment of CFS and comorbid mood disorders, CFS in primary school children, those who are severely affected, and those with refractory fatigue. We also need to start to develop an understanding of the biology of CFS/ME and whether different biological pathways are associated with different disease phenotypes. Some early studies with small sample studies suggest that an omic approach to dissecting out the different subtypes may help to clarify different biological pathways. ${ }^{73}$ This approach will require a large bioresource of well-characterized patients.

\section{Disclosure}

Prof Crawley is an unpaid medical advisor for the Sussex and Kent ME/CFS society.

\section{References}

1. Collin SM, Nikolaus S, Heron J, Knoop H, White PD, Crawley E. Chronic fatigue syndrome (CFS) symptom-based phenotypes in two clinical cohorts of adult patients in the UK and The Netherlands. $J P s y-$ chosom Res. 2016;81:14-23.

2. Collin SM, Nuevo R, van de Putte EM, Nijhof SL, Crawley E. Chronic fatigue syndrome (CFS) or myalgic encephalomyelitis (ME) is different in children compared to in adults: a study of UK and Dutch clinical cohorts. BMJ Open. 2015;5(10):e008830.

3. Carruthers BM, van de Sande MI, De Meirleir KL, et al. Myalgic encephalomyelitis: International Consensus Criteria. J Intern Med. 2011;270(4):327-338

4. Institute of Medicine. Beyond Myalgic Encephalomyelitis/Chronic Fatigue Syndrome: Redefining an Illness. Washington, DC, USA: National Academies Press; 2015.

5. Kennedy G, Underwood C, Belch JJ. Physical and functional impact of chronic fatigue syndrome/myalgic encephalomyelitis in childhood Pediatrics. 2010;125(6):e1324-e1330.

6. Velleman S, Collin SM, Beasant L, Crawley E. Psychological wellbeing and quality-of-life among siblings of paediatric CFS/ME patients: a mixed-methods study. Clin Child Psychol Psychiatry. 2016;21(4):618-633.

7. Missen A, Hollingworth W, Eaton N, Crawley E. The financial and psychological impacts on mothers of children with chronic fatigue syndrome (CFS/ME). Child Care Health Dev. 2012;38(4):505-512.

8. Collin SM, Bakken IJ, Nazareth I, Crawley E, White PD. Health care resource use by patients before and after a diagnosis of chronic fatigue syndrome (CFS/ME): a clinical practice research datalink study. $B M C$ Fam Pract. 2017;18(1):60

9. Crawley E, Sterne JA. Association between school absence and physical function in paediatric chronic fatigue syndrome/myalgic encephalopathy. Arch Dis Child. 2009;94(10):752-756.

10. Crawley E, Hunt L, Stallard P. Anxiety in children with CFS/ME. Eur Child Adolesc Psychiatry. 2009;18(11):683-689.

11. Bould H, Collin SM, Lewis G, Rimes K, Crawley E. Depression in paediatric chronic fatigue syndrome. Arch Dis Child. 2013;98(6): 425-428. 
12. Parslow RM, Harris S, Broughton J, et al. Children's experiences of chronic fatigue syndrome/myalgic encephalomyelitis (CFS/ME): a systematic review and meta-ethnography of qualitative studies. $B M J$ Open. 2017;7(1):e012633.

13. ter Wolbeek M, van Doornen LJ, Kavelaars A, Heijnen CJ. Severe fatigue in adolescents: a common phenomenon? Pediatrics. 2006;117(6):e1078-e1086.

14. Collin SM, Norris T, Nuevo R, et al. Chronic fatigue syndrome at age 16 years. Pediatrics. 2016;137(2):e20153434.

15. Mears CJ, Taylor RR, Jordan KM, Binns HJ; Pediatric Practice Research Group. Sociodemographic and symptom correlates of fatigue in an adolescent primary care sample. JAdolescHealth. 2004;35(6): 528e.21-6.

16. Chalder T, Goodman R, Wessely S, Hotopf M, Meltzer H. Epidemiology of chronic fatigue syndrome and self reported myalgic encephalomyelitis in 5-15 year olds: cross sectional study. BMJ. 2003;327(7416): 654-655.

17. Nijhof SL, Maijer K, Bleijenberg G, Uiterwaal CS, Kimpen JL, van de Putte EM. Adolescent chronic fatigue syndrome: prevalence, incidence, and morbidity. Pediatrics. 2011;127(5):e1169-e1175.

18. Crawley E, Hughes R, Northstone K, Tilling K, Emond A, Sterne JA. Chronic disabling fatigue at age 13 and association with family adversity. Pediatrics. 2012;130(1):e71-e79.

19. Crawley EM, Emond AM, Sterne JA. Unidentified chronic fatigue syndrome/myalgic encephalomyelitis (CFS/ME) is a major cause of school absence: surveillance outcomes from school-based clinics. $B M J$ Open. 2011;1(2):e000252.

20. Bakken I, Tveito K, Gunnes N, et al. Two age peaks in the incidence of chronic fatigue syndrome/myalgic encephalomyelitis: a populationbased registry study from Norway 2008 inverted question mark2012. BMC Med. 2014;12(1):167.

21. Webb CM, Collin SM, Deave T, Haig-Ferguson A, Spatz A, Crawley E. What stops children with a chronic illness accessing health care: a mixed methods study in children with Chronic Fatigue Syndrome/Myalgic Encephalomyelitis (CFS/ME). BMC Health Serv Res. 2011;11(1):308.

22. Bowen J, Pheby D, Charlett A, McNulty C. Chronic fatigue syndrome: a survey of GPs' attitudes and knowledge. Fam Pract. 2005;22(4): 389-393.

23. Rimes KA, Goodman R, Hotopf M, Wessely S, Meltzer H, Chalder T. Incidence, prognosis, and risk factors for fatigue and chronic fatigue syndrome in adolescents: a prospective community study. Pediatrics. 2007;119(3):e603-e609.

24. Haines LC, Saidi G, Cooke RW. Prevalence of severe fatigue in primary care. Arch Dis Child. 2005;90(4):367-368.

25. Buchwald D, Herrell R, Ashton S, et al. A twin study of chronic fatigue. Psychosom Med. 2001;63(6):936-943.

26. Hickie I, Kirk K, Martin N. Unique genetic and environmental determinants of prolonged fatigue: a twin study. Psychol Med. 1999;29(2):259-268.

27. Collin SM, Tilling K, Joinson C, et al. Maternal and childhood psychological factors predict chronic disabling fatigue at age 13 years. J Adolesc Health. 2015;56(2):181-187.

28. Katz BZ, Shiraishi Y, Mears CJ, Binns HJ, Taylor R. Chronic fatigue syndrome after infectious mononucleosis in adolescents. Pediatrics. 2009;124(1):189-193.

29. Donnachie E, Schneider A, Mehring M, Enck P. Incidence of irritable bowel syndrome and chronic fatigue following GI infection: a population-level study using routinely collected claims data. Gut. Epub 2017 Jun 10.

30. Hickie I, Davenport T, Wakefield D, et al; Dubbo Infection Outcomes Study Group. Post-infective and chronic fatigue syndromes precipitated by viral and non-viral pathogens: prospective cohort study. $B M J$. 2006;333(7568):575.

31. Rangel L, Garralda ME, Hall A, Woodham S. Psychiatric adjustment in chronic fatigue syndrome of childhood and in juvenile idiopathic arthritis. Psychol Med. 2003;33(2):289-297.
32. Taylor AK, Loades M, Brigden AL, Collin SM, Crawley E. "It's personal to me": a qualitative study of depression in young people with CFS/ ME. Clin Child Psychol Psychiatry. 2017;22(2):326-340.

33. Fisher H, Crawley E. Why do young people with CFS/ME feel anxious? A qualitative study. Clin Child Psychol Psychiatry. 2012;18(4):556-573.

34. Parslow R, Patel A, Beasant L, Haywood K, Johnson D, Crawley E. What matters to children with CFS/ME? A conceptual model as the first stage in developing a PROM. Arch Dis Child. 2015;100(12):1141-1147.

35. Bould H, Lewis G, Emond A, Crawley E. Depression and anxiety in children with CFS/ME: cause or effect? Arch Dis Child. 2011;96(3):211-214

36. Darbishire L, Seed P, Ridsdale L. Predictors of outcome following treatment for chronic fatigue. Br J Psychiatry. 2005;186(4):350-351.

37. Flo E, Chalder T. Prevalence and predictors of recovery from chronic fatigue syndrome in a routine clinical practice. Behav Res Ther. 2014;63:1-8.

38. Kempke S, Goossens L, Luyten P, Bekaert P, Van Houdenhove B, Van Wambeke P. Predictors of outcome in a multi-component treatment program for chronic fatigue syndrome. J Affect Disord. 2010;126(1-2):174-179.

39. Tummers M, Knoop H, van Dam A, Bleijenberg G. Moderators of the treatment response to guided self-instruction for chronic fatigue syndrome. J Psychosom Res. 2013;74(5):373-377.

40. Wearden AJ, Dunn G, Dowrick C, Morriss RK. Depressive symptoms and pragmatic rehabilitation for chronic fatigue syndrome. $B r J$ Psychiatry. 2012;201(3):227-232.

41. White PD, Thomas JM, Kangro HO, et al. Predictions and associations of fatigue syndromes and mood disorders that occur after infectious mononucleosis. Lancet. 2001;358(9297):1946-1954.

42. Prins J, Bleijenberg G, Rouweler EK, van der Meer J. Effect of psychiatric disorders on outcome of cognitive-behavioural therapy for chronic fatigue syndrome. Br J Psychiatry. 2005;187:184-185.

43. Loades ME, Sheils EA, Crawley E. Treatment for paediatric chronic fatigue syndrome or myalgic encephalomyelitis (CFS/ME) and comorbid depression: a systematic review. BMJ Open. 2016;6(10):e012271.

44. van de Putte EM, Uiterwaal CS, Bots ML, Kuis W, Kimpen JL, Engelbert $\mathrm{RH}$. Is chronic fatigue syndrome a connective tissue disorder? A crosssectional study in adolescents. Pediatrics. 2005;115(4):e415-e422.

45. Barron DF, Cohen BA, Geraghty MT, Violand R, Rowe PC. Joint hypermobility is more common in children with chronic fatigue syndrome than in healthy controls. J Pediatr. 2002;141(3):421-425.

46. Joyce J, Hotopf M, Wessely $\mathrm{S}$. The prognosis of chronic fatigue and chronic fatigue syndrome: a systematic review. QJM. 1997;90(3):223-233.

47. White PD, Goldsmith KA, Johnson AL, et al; PACE trial management group. Comparison of adaptive pacing therapy, cognitive behaviour therapy, graded exercise therapy, and specialist medical care for chronic fatigue syndrome (PACE): a randomised trial. Lancet. 2011;377(9768):823-836.

48. Hickie I, Davenport T, Vernon SD, et al; International Chronic Fatigue Syndrome Study Group. Are chronic fatigue and chronic fatigue syndrome valid clinical entities across countries and health-care settings? Aust N Z J Psychiatry. 2009;43(1):25-35.

49. Hickie I, Lloyd A, Hadzi-Pavlovic D, Parker G, Bird K, Wakefield D. Can the chronic fatigue syndrome be defined by distinct clinical features? Psychol Med. 1995;25(5):925-935.

50. Janal MN, Ciccone DS, Natelson BH. Sub-typing CFS patients on the basis of 'minor' symptoms. Biol Psychol. 2006;73(2):124-131.

51. Sullivan PF, Smith W, Buchwald D. Latent class analysis of symptoms associated with chronic fatigue syndrome and fibromyalgia. Psychol Med. 2002;32(5):881-888.

52. Aslakson E, Vollmer-Conna U, White PD. The validity of an empirical delineation of heterogeneity in chronic unexplained fatigue. Pharmacogenomics. 2006;7(3):365-373.

53. Williams TE, Chalder T, Sharpe M, White PD. Heterogeneity in chronic fatigue syndrome - empirically defined subgroups from the PACE trial. Psychol Med. 2017;47(8):1454-1465. 
54. May M, Emond A, Crawley E. Phenotypes of chronic fatigue syndrome in children and young people. Arch Dis Child. 2010;95(4):245-249.

55. Aslakson E, Vollmer-Conna U, Reeves WC, White PD. Replication of an empirical approach to delineate the heterogeneity of chronic unexplained fatigue. Popul Health Metr. 2009;7:17.

56. NICE. Chronic Fatigue Syndrome/Myalgic Encephalomyelitis (or encephalopathy): Diagnosis and Management of CFS/ME in Adults and Children (NICE guidelines CG53). London; 2007. CG53.

57. Rowe PC, Underhill RA, Friedman KJ, et al. Myalgic encephalomyelitis/ chronic fatigue syndrome diagnosis and management in young people: a primer. Front Pediatr. 2017;5:121.

58. Larun L, Brurberg KG, Odgaard-Jensen J, Price JR. Exercise as treatment for patients with chronic fatigue syndrome. Cochrane Database Syst Rev. 2015;2:CD003200.

59. Smith ME, Haney E, McDonagh M, et al. Treatment of myalgic encephalomyelitis/chronic fatigue syndrome: a systematic review for a National Institutes of Health Pathways to Prevention Workshop. Ann Intern Med. 2015;162(12):841-850.

60. Chambers D, Bagnall AM, Hempel S, Forbes C. Interventions for the treatment, management and rehabilitation of patients with chronic fatigue syndrome/myalgic encephalomyelitis: an updated systematic review. J R Soc Med. 2006;99(10):506-520.

61. Knight SJ, Scheinberg A, Harvey AR. Interventions in pediatric chronic fatigue syndrome/myalgic encephalomyelitis: a systematic review. J Adolesc Health. 2013;53(2):154-165.

62. Smith SN, Crawley E. Is there effective behavioural treatment for children with chronic fatigue syndrome/myalgic encephalomyelitis? Arch Dis Child. 2013;98(7):561-563.

63. Gordon BA, Knapman LM, Lubitz L. Graduated exercise training and progressive resistance training in adolescents with chronic fatigue syndrome: a randomized controlled pilot study. Clin Rehabil. 2010;24(12):1072-1079.

64. Loades ME, Chalder T. Same, same but different? cognitive behavioural treatment approaches for paediatric CFS/ME and depression - CORRIGENDUM. Behav Cogn Psychother. 2017;45(4):432.
65. Segal TY, Hindmarsh PC, Viner RM. Disturbed adrenal function in adolescents with chronic fatigue syndrome. J Pediatr Endocrinol Metab. 2005;18(3):295-302.

66. Nijhof SL, Rutten JM, Uiterwaal CS, Bleijenberg G, Kimpen JL, Putte EM. The role of hypocortisolism in chronic fatigue syndrome. Psychoneuroendocrinology. 2014;42:199-206.

67. Harris S, Gilbert M, Beasant L, Linney C, Broughton J, Crawley E. A qualitative investigation of eating difficulties in adolescents with chronic fatigue syndrome/myalgic encephalomyelitis. Clin Child Psychol Psychiatry. 2017;22(1):128-139.

68. Norris T, Hawton K, Hamilton-Shield J, Crawley E. Obesity in adolescents with chronic fatigue syndrome: an observational study. Arch Dis Child. 2017;102(1):35-39.

69. Haig-Ferguson A, Tucker P, Eaton N, Hunt L, Crawley E. Memory and attention problems in children with chronic fatigue syndrome or myalgic encephalopathy. Arch Dis Child. 2009;94(10):757-762.

70. Kawatani J, Mizuno K, Shiraishi S, et al. Cognitive dysfunction and mental fatigue in childhood chronic fatigue syndrome-a 6-month followup study. Brain Dev. 2011;33(10):832-841.

71. Mizuno K, Watanabe Y. Neurocognitive impairment in childhood chronic fatigue syndrome. Front Physiol. 2013;4:87.

72. Tucker P, Haig-Ferguson A, Eaton N, Crawley E. What to do about attention and memory problems in children with CFS/ME: a neuropsychological approach. Clin Child Psychol Psychiatry. 2011;16(2) 215-223.

73. Nagy-Szakal D, Williams BL, Mishra N, et al. Fecal metagenomic profiles in subgroups of patients with myalgic encephalomyelitis/chronic fatigue syndrome. Microbiome. 2017;5(1):44.

74. Sharpe MC, Archard LC, Banatvala JE, et al. A report - chronic fatigue syndrome: guidelines for research. JR Soc Med. 1991;84(2):118-121.

75. Fukuda K, Straus SE, Hickie I, et al. The chronic fatigue syndrome: a comprehensive approach to its definition and study. International Chronic Fatigue Syndrome Study Group. Ann Intern Med. 1994;121(12) 953-959.
Pediatric Health, Medicine and Therapeutics

\section{Publish your work in this journal}

Pediatric Health, Medicine and Therapeutics is an international, peerreviewed, open access journal publishing original research, reports, editorials, reviews and commentaries. All aspects of health maintenance, preventative measures and disease treatment interventions are addressed within the journal. Practitioners from all disciplines are invited to submit

\section{Dovepress}

their work as well as healthcare researchers and patient support groups. The manuscript management system is completely online and includes a very quick and fair peer-review system. Visit http://www.dovepress.com/ testimonials.php to read real quotes from published authors. 